\title{
Recurrent Childhood Gemistocytic Astrocytoma
}

National Cancer Institute

\section{Source}

National Cancer Institute. Recurrent Childhood Gemistocytic Astrocytoma. NCI

Thesaurus. Code C115362.

The reemergence of gemistocytic astrocytoma in childhood after a period of remission. 